\title{
Thinking of DINK family support for the aged
}

\author{
Che Wenfeng ${ }^{1 *}$, Li Bingkun ${ }^{2}$
}

\author{
${ }^{1,2}$ Harbin University of Commerce, Harbin, Heilongjiang, 150028, China \\ *Corresponding author.Email:934214942@qq.com
}

\begin{abstract}
On May 3, 2021, in order to actively respond to the aging population and further optimize the fertility policy, China officially implemented the "three child policy", which immediately aroused people's hot discussion and enthusiasm for having children. However, some people still insist on giving up childbearing and choosing DINK family model. Under the influence of the traditional concept of "raising children for old age", how to provide for the aged of DINK family has become a problem that makes people think deeply. This paper thinks about several problems existing in providing for the aged of DINK family, and further thinks about its countermeasures and suggestions, so as to make people treat this new family model more rationally.
\end{abstract}

Keywords: Family model, DINK family, Pension problem

\section{INTRODUCTION}

To understand DINK family, we should first understand the meaning of DINK. DINK, or "DINK" (double income no kids), refers to those people who have the ability to procreate and choose not to have children. In addition to actively not to have children, they may also passively choose not to have children for subjective or objective reasons. The DINK family generally refers to the working-class couples who do not have children [1]. Both husband and wife have income but no children. That is to say, the first condition to become a DINK family is a family with fertility but not fertility; Secondly, subjectively, we should accept and recognize our DINK identity, and think that DINK is a way of life, which is a very important factor; Finally, both husband and wife should have a stable income, and usually the upper class of society, the living standard is higher.

In essence, DINK family is also a childless family, but there are some differences between them. There are various factors leading to childless families, such as refusing to give birth due to economic and living factors, or having the desire to give birth but unable to give birth due to physical health reasons, and becoming a single child lost family due to the loss of children [2]. So understanding the meaning of DINK family is the key point of this paper.

\section{PROBLEMS IN DINK FAMILY PENSION}

\subsection{Psychological needs are hard to be comforted}

As a vulnerable group, the elderly need special care and care. The elderly not only need money and material care, but also need spiritual greetings and care in daily life, which is particularly prominent in DINK family. Both husband and wife of DINK family have stable income and good quality of life. Therefore, when they retire, their material life can be fully guaranteed by the endowment insurance they pay when they work. Compared with economic needs, spiritual comfort belongs to a higher level of needs, but because there are no children, they can not enjoy the happiness of family. In order to pursue freedom and high quality of life when young, they subjectively choose not to have children. When you are old, when you see the people around you with their children and grandchildren, you will inevitably feel envious and even regretful when you enjoy the festival. As time goes by, some DINK elderly people will even be depressed all day long, and they have serious psychological and even mental problems. Under the influence of this kind of emotion for a long time, and the growing age will seriously affect their health. 


\subsection{The service level of institutional care for the aged is single}

After the reform and opening up, with the implementation of family planning policy, the family structure of our country has changed, and the family size gradually becomes smaller. The traditional family pension model can not meet the elderly's needs for the elderly. For the elderly in DINK family, institutional pension is a good choice. By the end of December 2020, there are 38000 pension institutions in China. In recent years, the demand for the elderly institutions has been increasing. In general, the institutional pension is still in short supply and the service level of the elderly is uneven and the homogeneity is serious. For the elderly of DINK family, because of their rich life, the demand for high-quality elderly care institutions is particularly obvious. They pursue high-level daily life, such as calligraphy, dance and regular tourism. General elderly care institutions can not meet the actual needs of elderly DINK family no matter from the environment and service items. At present, the high-quality endowment institutions in China are concentrated in the developed city of Beijing, Shanghai and Guangzhou. The price is high and limited, even registered residence registration. The newly revised "management measures for the elderly institutions" was officially implemented in November 2020. It is clearly stated in the measures that the high-quality development of institutional pension services should be promoted. With the implementation of the policy, the elderly care institutions around the country will comprehensively improve the quality of elderly care services, so that every old man has a highquality and happy life.

\subsection{The level of community service is difficult to meet the personalized needs of the elderly in DINK family}

Although China's community pension system continues to improve, the scope of services continues to expand, and the types of services are more abundant, but in the face of increasing aging today, community pension services still need to be further strengthened. At present, the problems of the old-age service in the former community are mainly reflected in the incomplete community facilities, poor environment, lack of professional community service personnel, narrow service scope and so on. For the elderly in DINK family, most of the community services are limited to daily diet and housekeeping services, and they are "nannies" rather than "housekeepers". Most of the service centers in the community are mainly for entertainment. The elderly organize their own activities to kill time, such as playing cards and chatting. When the children go home to visit the elderly on weekends, it is difficult for the elderly of DINK family to get special "weekend service" in the community. Compared with the elderly with children, the elderly in DINK family need careful care and care, and their personalized life needs need to be met. China's community nursing service began to appear as early as the beginning of the 21 st century, but restricted by the level of economic development, especially the development of non first tier cities is very slow, although in recent years our country attaches great importance to the construction of pension industry professionals, but there are still a variety of problems.

\subsection{Financial management and insurance awareness need to be further strengthened}

Due to the pursuit of freedom and high quality of life when they were young, DINK family's consumption concept and consumption level are different from different families. They not only pay attention to the quality, price and brand of consumption, but also pay more attention to the spiritual satisfaction in the process of consumption, and their consumption level is higher than that of ordinary families. Therefore, it is particularly important to cultivate the concept of financial management. Most DINK families choose to "provide for the aged with housing", that is, according to their own resources, making use of the differences between the life cycle of housing and the remaining lives of elderly residents, they can cash out the huge real estate resources owned by the majority of elderly people, especially the remaining value of housing after people's death through certain financial or non-financial mechanisms. But at present, China's housing price level is stable, and there are huge differences in housing prices in different regions. The number of economically developed cities suitable for pension is limited, and the housing price is often several times higher than that in other regions. At present, it seems that the economic benefits of "housing for pension" are limited.After retirement, the wage income of the elderly in DINK family has declined. If we want to maintain the existing consumption level, we need to understand financial management and financial knowledge, and increase "non working income". Because DINK families have no children to take care of, it is difficult for them to get sick and stay in hospital every time when they are old. However, some DINK families lack the awareness of buying commercial insurance, which leads to the low proportion of insurance reimbursement after hospitalization, high personal payment of hospitalization expenses, the majority of husband and wife's savings are spent on seeing a doctor, the living standard plummets, and even leads to family conflicts. 


\section{SOLUTIONS TO THE PROBLEM OF DINK'S FAMILY PROVIDING FOR THE AGED}

\subsection{Build a communication platform,Travel for the aged}

Providing spiritual comfort for the elderly is the embodiment of social responsibility and traditional Chinese virtues. Social organizations can build a network platform for the elderly of DINK family to communicate. Everyone has similar experience and situation, so they will understand each other. The platform can be divided into provinces and cities. Because of eating habits, language communication and other factors, the elderly people in the same area can communicate more smoothly. Every weekend or holiday, they can even meet offline to communicate, share their own family stories, help each other, and make each other no longer lonely.

With the development of economy and the growth of tourism industry, tourism pension has become a new pension model for the elderly. The so-called tourism pension, also known as migratory bird pension, is a form of remote pension service, and it does not take immigration, work and settlement as the purpose, but a short tour, travel and temporary residence. For the elderly of DINK family, this is a very comfortable way to provide for the aged. The elderly can choose different places to support themselves according to the changes of seasons [3]. In winter, the elderly can go to warmer places, while in summer, they can go to cool places for summer. Tourism for the elderly can enrich their old life, improve their quality of life, and enjoy the beauty of life on the journey.

\subsection{Provide professional community services}

With the rapid development of China's economy, simple community services can no longer meet people's daily needs. Modern community services should also meet people's material and cultural needs. For the elderly of DINK family, the community should start with care services, fitness services, entertainment services and other services. For example, medical service centers and psychological care centers should be established in the community, and regular physical examination should be carried out for the elderly of DINK family. By using 5G technology of mobile Internet, artificial intelligence, big data and other cutting-edge scientific and technological means, informatization and community service will be deeply blended and extended, which will become the driving force for the sustainable innovation and development of community DINK family pension service mode. We should establish a normalized contact system, strengthen the information exchange in the process of elderly care service construction among various departments in the community, and dynamically update the elderly information and elderly care service content of DINK family in real time. Relying on the comprehensive service platform of smart community, the specific content and level of elderly care needs of DINK family are divided in detail, so as to lay the foundation for accurate service, establish a perfect elderly information database, and provide DINK family with the services they need.[4] At the same time, professional training for community managers and service personnel, the establishment of appropriate files for the elderly DINK family, regular visits and greetings from professional social workers, every traditional festival to send love activities, so that the elderly feel the warmth of society.

\subsection{Enhance the ability of family savings and improve family security}

In addition to preparing the family's daily expenses and emergency funds, the elderly of DINK family should reasonably use their surplus wealth for financial management, so as to stabilize their source of wealth [5].For example, to invest in treasury bonds instead of bank time deposits, while ensuring the safety and liquidity of funds, increase higher wealth returns, or invest funds in stocks, funds, bonds, etc. according to a certain proportion for risk sharing. In addition, we should broaden our investment horizons, and appropriately buy stamps and commemorative coins when young, so as to cultivate interests and hobbies, There is room for appreciation.

Commercial insurance is a good supplement to social insurance. DINK family can use part of their property to take out insurance, especially medical insurance such as major disease insurance, hospitalization medical insurance, nursing insurance and accident injury insurance. When choosing commercial insurance companies, they should choose companies with good insurance period, insurance conditions and large capital income, so as to ensure the safety and reliability of insurance income, We should truly realize the goal of providing for the elderly.

\section{CONCLUSION}

DINK appeared in Europe and America in the 1960s and was introduced into China in the 1980s. Now more than 40 years later, the first DINK have entered middle age. At present, China's "DINK group" is growing, with more than 600000 people. With the enrichment of material life, the satisfaction of spiritual life and the yearning for freedom, contemporary youth's acceptance of DINK family has also increased. This shows that in the future, there will be more and more DINK family elderly. In the face of this kind of "emerging" elderly groups, both institutional organizations and community 
services should provide professional and personalized services. The elderly of DINK family should also learn the knowledge of insurance and finance, and give themselves a rich and happy old age.

\section{REFERENCES}

[1] Xu Bin. Sociological investigation of DINK family [J]. Guangxi Social Sciences, 2005 (01): 160-162

[2] Meng Nana. Thinking on DINK family and its pension problem [J]. Reform and opening up, 2016 (16): $83+85$

[3] Li Xiao. Analysis on the integrated development of pension service industry and tourism [J]. China industry economics, 2020 (02): 73-74

[4] Zhao Na. Problems and Countermeasures of community home-based care service [J]. Journal of economic research, 2021 (08): 82-84

[5] Pan Zhangyun DINK: financial export under the pressure of pension [j]. Happy family, 2014 (02): 23 